The Journal of Laryngology \& Otology

http://journals.cambridge.org/JLO

Additional services for The Journal of Laryngology \& Otology:

Email alerts: $\underline{\text { Click here }}$

Subscriptions: $\underline{\text { Click here }}$

Commercial reprints: $\underline{\text { Click here }}$

Terms of use : $\underline{\text { Click here }}$

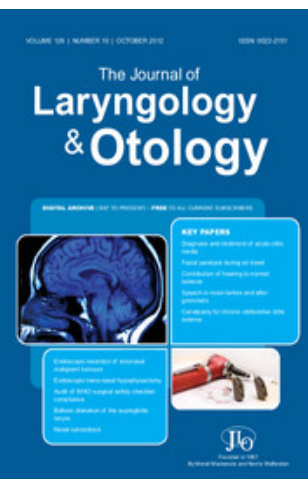

\title{
Useful residual hearing despite radiological findings suggestive of anacusis
}

Doris Eva Bamiou, Cliodna O Mahoney and Tony Sirimanna

The Journal of Laryngology \& Otology / Volume 113 / Issue 08 / August 1999, pp 714 - 716

DOI: 10.1017/S0022215100145001, Published online: 29 June 2007

Link to this article: http://journals.cambridge.org/abstract_S0022215100145001

How to cite this article:

Doris Eva Bamiou, Cliodna O Mahoney and Tony Sirimanna (1999). Useful residual hearing despite radiological findings suggestive of anacusis. The Journal of Laryngology \& Otology, 113, pp 714-716 doi:10.1017/S0022215100145001

Request Permissions : $\underline{\text { Click here }}$ 


\title{
Useful residual hearing despite radiological findings suggestive of anacusis
}

\author{
Doris Eva Bamiou, M.Sc. (UK), Cliodna O Mahoney, M.R.C.P.(I), M.R.C.G.P., M.Sc.,
} Tony Sirimanna, M.S., F.R.C.S., D.L.O., M.Sc.

\begin{abstract}
A severe malformation of the inner ear, often referred to as severe labyrinthine dysplasia or common cavity deformity, consists of an absent or dilated cochlear basal coil, wide communication with the vestibule and a tapered internal acoustic meatus and can be associated with absent hearing. We discuss two children with severe labyrinthine dysplasia as shown by computed tomography (CT) scans and, in the first case, an absent VIIIth nerve bilaterally shown by magnetic resonance imaging (MRI). In 1995, both cases were precluded from cochlear implantation, on the basis of the absent VIIIth nerve (first case) and increased risk of CSF leak during operation (second case). However, audiometric results and vocalization patterns of both children suggested the presence of some residual hearing function, while recently reported specific surgical techniques have been found to be safe and effective in the cochlear implantation of the common cavity deformity. The management of such cases should be decided on the grounds of a full audiological assessment in conjunction with the radiological features, in the light of current surgical trends shown to be safe and effective.
\end{abstract}

Key words: Labyrinth; Dysplasia; Cochlear implant

\section{Introduction}

Morphogenetic defects of the inner ear are gross structural malformations caused by early disruption of the development of the inner ear in utero (Steel, 1995; Steel and Brown, 1996), and may occur in 3.8 to 6.8 per cent of cases with sensorineural hearing loss (Zalzal et al., 1986; Woolford et al., 1995). The classification and nomenclature of these structural abnormalities have been long standing causes of debate (Ormerod, 1960; Jackler et al., 1987), leading to confusion regarding the hearing status and appropriate management of patients with such abnormalities.

Phelps $(1990 ; 1992)$ has shown the distinction between a true Mondini deformity, which describes a cochlea with a basal turn and a distal sac, and a more severe type of dysplasia, termed severe labyrinthine dysplasia, pseudo-Mondini, or common cavity (Jackler et al., 1987) consisting of an absent or dilated basal coil, wide communication with a dilated vestibule and often a tapered ended internal acoustic meatus. Patients with a Mondini deformity may have some hearing present and are good candidates for cochlear implantation (Phelps, 1992). The common cavity deformity is reported to be associated with a risk of spontaneous CSF fistula and meningitis (Phelps et al., 1994) and of intra-operative CSF gusher (McElveen et al., 1997). There is also a risk of post-operative CSF leakage and meningitis (Page and Eby, 1997). In addition, the deformity could also be associated with anacusis due to the absent VIIIth nerve and for all these reasons, these cases have been thought to be not eligible for cochlear implantation (Phelps, 1992; Phelps et al., 1993). However, a post mortem histological section has shown the presence of some neural elements in such a common cavity (Phelps et al., 1994). In addition, Luntz and co-workers (1997) reported successful cochlear implantation of patients with a common cavity, although with less certain results than in other inner ear malformations.

We report the cases of two children with severe labyrinthine deformities of the inner ear and radiological findings suggestive of an absent VIIIth nerve, whose clinical presentation and audiometric findings suggested the presence of some residual hearing function.

\section{Case 1}

A 16-month-old African girl was referred to the Audiology department in Great Ormond Street Hospital with a history of being unresponsive to sound and delayed speech and language. Her parents were second cousins. Birth was induced at 38 weeks because of maternal hypertension, but 
otherwise the perinatal and postnatal course was uneventful. Her motor milestones were normal.

Otoscopy and tympanometry were normal. In the distraction test, unaided thresholds were 90-100 dBA between $500-4000 \mathrm{~Hz}$ bilaterally. Brain stemevoked response (BSER) showed no response at $100 \mathrm{dBNHL}$ on the right side with wave I present at $95 \mathrm{dBNHL}$ on the left side. She was fitted with two post-aural hearing aids with which her aided thresholds were $60-65 \mathrm{dBA}$ between $500-1000 \mathrm{~Hz}$ and $90 \mathrm{dBA}$ at 2000 and $4000 \mathrm{~Hz}$. In addition, a marked increase in vocalization was noted with the hearing aids in situ.

A CT scan of the petrous pyramids/internal acoustic meatuses demonstrated presence of a primitive sac instead of a cochlea on the left (severe labyrinthine dysplasia) and an absent cochlea on the right, dilated vestibules confluent with the dysplastic lateral semicircular canals and narrow and tapering internal acoustic meatuses on both sides. The interpretation of the CT findings suggested an increased risk of CSF gusher during operation and post-operative recurrent meningitis, as well as the possible absence of the VIIIth nerve. The external and middle ears were normal bilaterally. A subsequent MRI scan failed to identify the VIIIth nerve on either side.

On the basis of the radiological findings, the parents withdrew amplification and the child was lost to follow-up for two years. On review at that stage, amplification was re-introduced. This resulted in increased responsiveness to sound and improved vocalizations, including repetition of monosyllabic words. At the age of 5.5 years, the child had 10 clear words in English, many more in sign and vocalized when signing. Her free field aided thresholds were 65 to $80 \mathrm{dBA}$ between 250 to $4000 \mathrm{~Hz}$. Her pure tone audiogram thresholds were $120 \mathrm{dBHL}$ at 500 to $2000 \mathrm{~Hz}$ on the right, and $105 \mathrm{dBHL}$ at 500 to 1000 $\mathrm{Hz}$ and $115 \mathrm{dBHL}$ at 2000 to $40000 \mathrm{~Hz}$ on the left.

It was concluded that there was some degree of residual hearing, possibly due to some remnants of neural connection in the grossly deformed labyrinths that the MRI failed to identify, due to resolution limits. Nevertheless, it was decided at the time (in 1995) that the child was not eligible for cochlear implantation, due to an increased risk of CSF gusher during operation or post-operative CSF fistula and meningitis.

\section{Case 2}

An 11-month-old Bengali girl was referred to the Donald Winicott Child Development Centre for audiological assessment. There was no other past medical history of relevance apart from an unconfirmed history of hearing loss in the family. Motor milestones were age appropriate. She was diagnosed as having a bilateral profound sensorineural hearing loss, on the basis of distraction testing, which showed some responses to non-frequency specific sounds at 100-110 dBA, and of BSER with no responses up to $100 \mathrm{dBNHL}$ on the right and a threshold of $95 \mathrm{dBNHL}$ on the left.

A CT scan of her petrous pyramids/internal acoustic meatuses demonstrated normal external, middle ears and mastoids, but grossly deformed and underdeveloped labyrinths. There was a primitive otocyst on the left. On the right, there was a dilated and dysplastic cochlea, continuous with the dilated vestibule. Both internal acoustic meatuses were narrow and tapering, suggesting absence or hypoplasia of the cochlear nerve.

She was given a trial of amplification and, at the age of two years and three months, was observed to have improved responsiveness to sound and to have three to four clear words. Following fitting with body-worn hearing aids, she was able to discriminate one, two, three and four syllable words from each other in a structured situation without any visual clues. The free field aided thresholds (aged four years) with the body worn hearing aid were 55 to $70 \mathrm{dBA}$ between 500 and $4000 \mathrm{~Hz}$. The pure tone audiogram thresholds were 105 at $500 \mathrm{~Hz}$ and of $120 \mathrm{dBHL}$ at 1000 to $4000 \mathrm{~Hz}$ on the right, and $105 \mathrm{dBHL}$ at $500 \mathrm{~Hz}, 120 \mathrm{dBHL}$ at 1000 , and 110 at $2000 \mathrm{~Hz}$ on the left.

It was concluded that some auditory function must be present in the grossly deformed ears. However, the consensus at the time (1994-1995) was that the child was not eligible for cochlear implantation, due to the absence of a defined cochlea on the left, and to the increased risk of an intra-operative CSF gusher on the right.

\section{Discussion}

In both children, the radiological findings suggested absence of hearing, according to published reports of similar cases (Phelps, 1992; Phelps et al., 1994), and possibly ineligibility for cochlear implantation, due to the risk of CSF leak at operation and the absence of the VIIIth nerves. These conclusions, however, may be challenged on several grounds.

The findings on audiological assessment strongly support the presence of residual function of the organ of Corti and VIIIth nerve. Some of the observed responses are unlikely to be vibrotactile, as Boothroyd and Cawkwell (1970), who measured vibrotactile thresholds to sound via ear phones, found these to be above $120 \mathrm{dBHL}$ for $1000 \mathrm{~Hz}$ and above $130 \mathrm{dBHL}$ for $2000 \mathrm{~Hz}$.

The vocalization patterns and sound discrimination abilities of our two cases also indicated the presence of hearing. Canonical babbling does not occur before 12 months in children with hearing loss (Kent et al., 1987), and does not proceed in a linear fashion (Steffens et al., 1994). In the case of complete deafness, however, it has been reported that canonical babbling may only develop following the fitting of vibrotactile aids (Lynch et al., 1989). In addition, both our cases were able to discriminate syllabic pattern contrasts which can become accessible at a minimum average hearing level of 115 dBHL (Boothroyd, 1984).

The labyrinthine deformity found in our two cases (first described by Edward Cock and later confused with the Mondini malformation (Phelps, 1992; 1994)) is currently termed severe labyrinthine dysplasia (Phelps, 1990; 1992) or common cavity deformity (Jackler et al., 1987). Hearing function was reported 
to be absent in severe labyrinthine dysplasia, based on histopathology grounds (Phelps, 1990; Phelps et al., 1993). Paparella (1980), however, has described the presence of some cochlear epithelial remnants and of scarce neural element in a similar case (which, interestingly, was classified as Mondini's deformity). Similarly, Phelps et al. (1994) demonstrated neural elements in a post mortem histological section of a common cavity. Jackler and co-workers (1987) reported median average thresholds of 94 dBHL in 19 ears of patients with a common cavity deformity. In the same study, patients with the common cavity deformity and very narrow IAMs in addition, tended to have average thresholds of $103 \mathrm{dBHL}$, while in nine ears thresholds were worse than $121 \mathrm{dBHL}$, and possibly vibrotactile.

In both our cases, CT and MRI indicated the possible absence of the VIIIth nerve. CT scans, however, do not provide enough information on the cochlear nerve, while the MRI study that was conducted on the first child would fail to identify the presence of a cochlear nerve of calibre less than $3 \mathrm{~mm}$. Such a rudimentary cochlear nerve would be sufficient to conduct some auditory information from the cochlear epithelial remnants to higher centres. This hypothesis is consistent with the presence of non-robust but traceable BSER in both cases, as well as with Phelps and co-workers' report (1994) on the presence of neural elements in an ear consisting of a large amorphous cavity, widely communicating with the sub-arachnoid space. The same imaging technique considerations would also apply when discussing appropriate rehabilitation and operation risks, as a thin bony partition might not be demonstrated by the CT scan, due to partial volume averaging (Phelps and Michaels, 1995).

Both children were excluded from cochlear implantation, as, at the time of their assessment (in 1995) the common cavity deformity was thought to carry a greater risk of post-operative meningitis, due to CSF leak at the time of operation, and consequently to have very poor prognosis regarding the implantation results. However, more recent papers (Hoffman et al., 1997; Luntz et al., 1997; McElveen et al., 1997) report specific surgical techniques as effective in implanting children with common cavity deformities. There has been one case report of the recurrence of a CSF fistula, with meningitis, after head trauma two years following cochlear implantation, in a common cavity case that had had a CSF gusher during the original operation (Page and Eby, 1997). This was successfully managed by packing the CSF leak site. Thus, the presence of the common cavity deformity can no longer be a contra-indication for cochlear implantation in itself.

In conclusion, the radiological findings in cases with congenital hearing loss need to be interpreted with caution, due to the limitations of imaging techniques, the lack of a universally accepted nomenclature for cochlear structural abnormalities, and the lack of clear-cut correlations between radiological and histopathological findings and between radiological appearances and hearing func- tion. The management of profoundly hearing impaired patients with cochlear deformities should be decided on the grounds of a full audiological assessment in conjunction with the radiological features, and in the light of current surgical trends, shown to be safe and effective.

\section{References}

Boothroyd, A. (1984) Auditory perception of speech contrasts by subjects with sensorineural hearing loss. Journal of Speech and Hearing Research 27: 134-144.

Boothroyd, A., Cawkwell, S. (1970) Vibrotactile thresholds in pure tone audiometry. Acta Otolaryngologica 69: 381-387.

Hoffman, R. A., Downey, L. L., Waltzman, S. B., Cohen, N. L. (1997) Cochlear implantation in children with cochlear malformations. American Journal of Otology 18: 184-187.

Jackler, R. K., Luxford, W. M., House, W. F. (1987) Congenital malformations of the middle ear: A classification based on embryogenesis. Laryngoscope 97: 2-14.

Kent, R. D., Osberger, M. J., Netshell, R., Hustedde, S. G. (1987) Phonetic development in identical twins who differ in auditory function. Journal of Speech and Hearing Disorders 52: 64-75.

Luntz, M., Balkany, T., Hodges, A. V., Telischi, F. F. (1997) Cochlear implants in children with congenital inner ear malformations. Archives of Otolaryngology - Head and Neck Surgery 123(9): 974-977.

Lynch, M. P., Oller, D. K., Steffens, M. (1989) Development of speech-like vocalizations in a child with congenital absence of cochleas: the case of total deafness. Applied Psycholinguistics 10: 315-333.

McElveen, J. T., Carasco, V. N., Miyamoto, R. T., Linthreum, F. H. (1997) Cochlear implantation in common cavity malformations using a transmastoid labyrinthotomy approach. Laryngoscope 107: 1032-1036.

Ormerod, F. C. (1960) The pathology of congenital deafness. Journal of Laryngology and Otology 74: 919-950.

Page, E. L., Eby, T. L. (1997) Meningitis after cochlear implantation in Mondini malformation. Otolaryngology Head and Neck Surgery 116(1): 104-106.

Paparella, M. M. (1980) Mondini's deafness. A review of histopathology. Annals of Otology, Rhinology Laryngology 89 (Suppl 69): 1-10.

Phelps, P. D. (1990) Mondini and 'Pseudo Mondini'. Clinical Otolaryngology 15: $99-101$.

Phelps, P. D. (1992) The basal turn of the cochlea. British Journal of Radiology 65: 370-374.

Phelps, P. D. (1994) Ear dysplasia after Mondini. Journal of Laryngology and Otology 108: 461-465.

Phelps, P. D., King, A., Michaels, L. (1994) Cochlear dysplasia and meningitis. American Journal of Otology 15: 551-557.

Phelps, P. D., Michaels, L. S. (1995) The common cavity congenital deformity of the inner ear. $O R L$ 57: 228-231.

Phelps, P. D., Proops, D., Sellars, S., Evans, J., Michaels, L. (1993) Congenital cerebrospinal fluid fistula through the middle ear and meningitis. Journal of Laryngology and Otology 107: 492-495.

Steel, K. P. (1995) Inherited hearing defects in mice. Annual Review of Genetics 29: 675-701.

Steel, K. P., Brown, S. D. M. (1996) Genetics of deafness. Current Opinion in Neurobiology 6: 520-525.

Steffens, M. L., Eilers, R. E., Fishman, L., Oller, D. K., Urbano, R. C. (1994) Early vocal development in tactually aided children with severe-profound hearing loss. Journal of Speech and Hearing Research 37: 700-711.

Woolford, T. J., Roberts, G. R., Hartley, C., Ramsden, R. T. (1995) Etiology of hearing loss and cochlear computed tomography: findings in preimplant assessment. Annals of Otology - Rhinology and Laryngology (Suppl 166): 201-206.

Zalzal, G. H., Shott, S. R., Towbin, R., Cotton, R. T. (1986) CT scan in the diagnosis of temporal bone diseases in children. Laryngoscope 96: 27-32.

Address for correspondence:

Dr D. E. Bamiou,

Audiology Department,

Great Ormond Street Hospital,

London WC1N 3JH.

e-mail: doriseva@ndirect.co.uk. 